\title{
Modo de reproducción escolar en las clases sociales cordobesas. Un análisis desde las transmisiones intergeneracionales ${ }^{1}$
}

\author{
Cecilia Jiménez Zunino ${ }^{2}$
}

Fecha de recepción: 23 de agosto de 2019

Fecha de aprobación: 3 de octubre de 2019

Fecha de publicación: 31 de diciembre de 2019

\begin{abstract}
Resumen
El artículo busca comprender el modo en que familias pertenecientes a diferentes clases sociales de Gran Córdoba realizan esfuerzos de inversión escolar para lograr mejorar las posiciones de sus descendientes. El texto se apoya en materiales empíricos cuantitativos y cualitativos. En un primer momento, reconstruimos las posiciones en el espacio social de las diferentes clases sociales en Córdoba (Argentina) desde métodos estadísticos. En un segundo momento realizamos entrevistas en profundidad a referentes de hogar de diferentes clases sociales. Desde las posiciones actuales de los entrevistados, accedimos a las modalidades que asume el modo de reproducción escolar de los entrevistados de diferentes clases sociales en las trayectorias intergeneracionales. Esto permitió conectar los momentos de las familias, mediados por la consideración del género y los ciclos vitales, con los diferentes momentos históricos de la estructura social y, particularmente, del sistema educativo.
\end{abstract}

Palabras clave: Córdoba (Argentina), familias, inversiones escolares, reproducción social intergeneracional.

\section{School reproduction made in Córdoba's social classes. An analysis based on intergenerational transmission}

\begin{abstract}
The article seeks to understand the way in which families belonging to different social classes in Córdoba make school investment efforts to improve the
\end{abstract}

Una versión anterior de este texto fue presentada en el V Seminario Internacional Desigualdad y Movilidad Social en América Latina, 6 a 8 de mayo de 2019, Santiago de Chile, Chile.

2 Doctora en Sociología, Universidad Complutense de Madrid, España. Investigadora Adjunta del Consejo Nacional de Investigaciones Científicas y Técnicas (CONICET, Argentina). Contacto: ceciliazunino@hotmail.com 
Modo de reproducción escolar en las clases sociales cordobesas. Un análisis desde las transmisiones intergeneracionales - Jiménez

positions of their descendants. The text is based on quantitative and qualitative empirical materials. Initially, the positions in society in the different social classes in Córdoba (Argentina) were reconstructed using statistical methods. In the second stage, in-depth interviews were conducted with the heads of households from various social classes. From the interviewees' current position, we accessed the modalities assumed by their social reproduction of the different social classes based on schooling and intergenerational trajectories. Downward mobility or maintenance trajectories in class position were traced, connecting the moments within the families and their life cycles with the different historical moments of the social structure and, particularly, the education system.

Key words: Córdoba (Argentina), families, intergenerational social reproduction, schooling investments

\section{Modo de reprodução escolar nas classes sociais cordobesas. Uma análise a partir das transmissões intergeracionais}

Resumo

$\mathrm{O}$ artigo procura compreender a forma em que famílias pertencentes a diferentes classes sociais da Grande Córdoba realizam esforços de investimento escolar para conseguir melhorar as posições de seus descendentes. $\mathrm{O}$ texto está sustentado em materiais empíricos quantitativos e qualitativos. Em um primeiro momento, reconstruímos as posições no espaço social das diferentes classes sociais em Córdoba (Argentina) desde métodos estatísticos. Em um segundo momento, realizamos entrevistas aprofundadas a chefes de família de diferentes classes sociais. A partir das posições atuais dos entrevistados, verificamos as modalidades que assume o modo de reprodução escolar dos entrevistados de diferentes classes sociais nas trajetórias intergeracionais. Isto permitiu conectar os momentos das famílias, através da consideração do gênero e dos ciclos vitais, com os diferentes momentos históricos da estrutura social e, particularmente, do sistema educacional.

Palavras-chave: Córdoba (Argentina), famílias, investimentos escolares, reprodução social intergeracional.

\section{Introducción}

En este texto se analizan las inversiones escolares en la reproducción social de los miembros de familias cordobesas posicionados en distintas clases y fracciones de clase del espacio social de Gran Córdoba. Desde una perspectiva intergeneracional, observamos las apuestas educativas articuladas con las inserciones laborales de los entrevistados y sus familias (actuales y de origen) 
con el objetivo de identificar tendencias persistentes y rupturas o inflexiones en las trayectorias familiares.

Los estudios de movilidad social han incorporado diferentes dimensiones en las que se puede inferir el proceso de transmisión intergeneracional al interior de los hogares a través de las dinámicas familiares: estudios de movilidad educativa, de movilidad ocupacional, de movilidad de ingresos, etc. (Carabaña, 1999; Mediavilla \& Calero, 2010; Solís, 2018). Estos enfoques trabajan con datos agregados que se apoyan en una comparación entre las posiciones de origen (por ejemplo, considerando la ocupación del padre del encuestado cuando este tenía 16 años) y las de destino (la del propio entrevistado) ${ }^{3}$. Como han señalado Bertaux y Thompson (2009), si bien constituyen un insumo de trabajo fundamental para analizar la desigualdad social, los estudios de estratificación y movilidad social presentan algunas limitaciones. En primer lugar, el individualismo metodológico, que no considera los contextos familiares donde el sujeto entrevistado es producido (más allá de la ocupación paterna) y donde adquiere sus características y competencias sociales - no solo recursos económicos, sino también culturales, relacionales, energía moral y psíquica. En segundo lugar, la consideración de las mujeres solo como trabajadoras - en caso de que sean consideradas-, sin atender a otros repertorios de acción (como esposas, hermanas, madres, tías, abuelas, etc.). Desde estos papeles, como veremos en el análisis empírico, las mujeres también influyen en la vida familiar y en los posicionamientos sociales. Por último, al considerarse en las muestras sobre movilidad y estratificación social solo la ocupación masculina, se pierde riqueza analítica y contextual (Bertaux \& Thompson, 2009).

No podemos establecer aquí una discusión in extenso sobre los estudios de movilidad social, pero señalamos algunas de las limitaciones a la hora de visualizar la reproducción social e inferir los posicionamientos de clase: el papel asignado a la mujer — tanto si consideran su ocupación, como si no (Crompton, 1997; Jorrat, 2008); la exclusión muestral de quienes no responden al modelo de familia nuclear heteronormativo (Gómez-Rojas \& Riveiro, 2014). 
Aquí proponemos retomar esta línea de análisis para profundizar sobre los aspectos microsociológicos implicados en la reproducción social de las diferentes clases sociales de Gran Cór$\mathrm{doba}^{4}$, respecto a las apuestas educativas. La familia, especie de "caja negra" de la reproducción social, es también distribuidora de sus recursos relativos entre los descendientes ${ }^{5}$. El conjunto de condicionamientos estructurales se recrea a través de prácticas concretas en las familias de modos diferentes y según variables que exceden las tradicionales consideradas en los estudios sobre la estructura social ${ }^{6}$. La posición en la fratría, el género, las migraciones rural-urbanas de algunos miembros, etc., configuran conjuntos diferenciales de posibilidades de las inversiones escolares y las inserciones laborales (para ego y descendientes). Podemos afirmar, así, que la movilidad social no es un fenómeno individual, sino que pone en juego a toda la familia (Peugny, 2012). Además, esta forma de enfocar el problema nos lleva a conectar las esferas que, desde los estudios de género, se denominan productivas y reproductivas, lo que equivale a decir que se vinculan dimensiones públicas y privadas, o del trabajo remunerado y no remunerado.

4 El Instituto Nacional de Estadísticas y Censos (INDEC) considera "Gran Córdoba" a la conurbación de la ciudad de Córdoba (Argentina) con un conjunto de localidades del departamento Colón, ubicadas al norte de esta ciudad. Comprende Córdoba Capital, La Calera, Villa Allende, Río Ceballos, Unquillo, Salsipuedes, Mendiolaza, Saldán, La Granja, Agua de Oro, El Manzano y Guiñazú Norte. Según el Censo 2010, el Gran Córdoba cuenta con 1.412.182 habitantes (1.368.301 en 2001) en una superficie de $21.000 \mathrm{~km}^{2}$, lo que la constituye en la segunda aglomeración urbana del país en cuanto a población y superficie.

5 Las familias, de acuerdo con Bourdieu (1997), constituyen "uno de los lugares por antonomasia de la acumulación de capital bajo sus diferentes especies y de su transmisión entre las generaciones: salvaguarda su unidad para la transmisión y por la transmisión" (p. 133). De este modo, colaboran en la reproducción de la estructura del espacio social y de las relaciones de clase. El peso de las familias de origen es incalculable, puesto que se expresa en actos infinitesimales de socialización y oficialización.

6 El trabajo de Fanny Jedlicki (2018) explora las trayectorias escolares y residenciales diferenciales de miembros de una misma fratría en familias de medio rural del oeste francés, desde el encuadre de las economías afectivas. Esto supone atender a las dinámicas horizontales, entre hermanos, además de las verticales, de padres a hijos, que sugieren los estudios de movilidad social intergeneracional. 


\section{Modo de reproducción escolar como "modo de generación"}

La literatura especializada analiza dos ítems complementarios en la indagación de la desigualdad social: el análisis de los "modos de generación" y los "modos de reproducción social" (Bourdieu, 2011; Martín Criado, 1998; Mauger, 2013). Si el primer concepto permite dar cuenta de las semejanzas en las condiciones sociales que son producto de una época (como puede ser el estado de los instrumentos de reproducción social), el segundo atiende a las diferencias por clase social, debido al desigual acceso a los recursos potencialmente disponibles para el conjunto. Concretamente, la preponderancia creciente que ha adquirido el "modo de reproducción con componente escolar" (Mauger, 2013) impacta sobre todas las clases sociales, aunque de manera diferente de acuerdo con su patrimonio, generando una gran dispersión de las trayectorias vistas desde el plano intergeneracional.

La dimensión intergeneracional de la reproducción social (que permite ver las transmisiones en el tiempo histórico-social) y la dimensión intrageneracional (análisis de fratrías) son claves para comprender las dinámicas familiares de las diferentes clases sociales. El análisis de las fratrías está asentado en el terreno de la antropología y la historia (Fine, 2006), pero no ha sido tan utilizado en los estudios sociológicos sobre la movilidad social. Permite despejar, por ejemplo, quién de los hermanos es el heredero del capital en un grupo doméstico o cuál es el que se elige para hacer los mayores esfuerzos en acumular capital cultural, etc. Esto ocurre como una dimensión de la reproducción intrageneracional de acuerdo con las posiciones en el espacio social y la distribución de capitales a transmitir. Junto con la posición a nivel familiar entre los hermanos, interesa su género. Ambas variables han sido consideradas como fundamentales en el estudio de las genealogías en Europa, pero están menos profundizadas en los estudios sobre desigualdad y estructura social en nuestra región. 
Por otra parte, algunos estudios sobre clases sociales vienen alertando sobre la desinstitucionalización de las desigualdades, que pondría en tela de juicio las reglas que orientaban la promoción social en las últimas décadas (Chauvel, 2006). De acuerdo con este autor, se llega actualmente a procesos de repatrimonialización (Chauvel, 2016) que radicalizan las diferencias entre los herederos protegidos (fundamentalmente, gracias al capital económico) y los detentadores de diplomas (vale decir, el capital cultural), depreciados en el mercado laboral. Otros autores hablan de crisis de sucesión en las familias, que refiere a los problemas en la transmisión intergeneracional. De Gaulejac (2003) ha sugerido que el modelo de reproducción de clases sociales elaborado por Pierre Bourdieu funcionaba hasta 1970. Sin embargo, las importantes transformaciones sociales actuales (laborales, tecnológicas, familiares) colapsarían la ideología de autorrealización, exigida actualmente por las carreras profesionales, ante la incapacidad estructural para realizar esa autonomía. Además de las transformaciones del campo escolar, como señala Collin (2003) los cambios en las familias (menos durables, menos compactas, más desinstitucionalizadas, etc.) inciden en las formas de transmisión entre las generaciones.

Ahora bien, ¿qué implica esto para entender la desigualdad social, es decir, las oportunidades diferencialmente repartidas de poder realizar inversiones efectivas (y exitosas) en el mercado escolar? Mientras las clases medias y altas pueden, en gran medida, escalar posiciones por el canal credencialista de las carreras universitarias, las clases obrera y precaria, ¿acaso, socavaron el valor de la formación profesional y de las inserciones obreras - sumado a la crisis de empleo en general y a la desindustrializaciónal prolongar sus estudios en el sistema escolar, como sostienen Beaud y Pialoux (2014)?

Como viene siendo ampliamente estudiado, las clases populares y las clases medias se apoyan crecientemente en el mandato de estudiar y acumular capital escolar entre sus estrategias de reproducción social (Bourdieu, 1998, 2011; Jiménez Zunino \& 
Assusa, 2017; Lahire, 1995; Martín Criado, 1998; Terrail, 1984). El aumento de años de educación formal es un recorrido que se impone con fuerza en el ideario de progreso social, a pesar de que en los últimos años se ha desenganchado la ecuación educaciónocupación-remuneración (Franco \& Hopenhayn, 2010; Kessler \& Espinosa, 2003; Mora Salas, 2008).

Para el caso argentino, Luci y Gessaghi (2016) analizaron que no hay un mecanismo institucionalizado de meritocracia formal específico para posicionar a las élites (como puede identificarse para el caso francés), aunque la vía escolar supone una forma de acceder a posiciones de manager $\mathrm{y}$, eventualmente, a las familias tradicionales para algunas fracciones de las clases medias. Así, afirman que:

No existiendo circuitos educativos formales para la producción de una élite, el reclutamiento a los máximos cargos de conducción pone en "igualdad de condiciones" a jóvenes profesionales de clase media que, egresados de las universidades públicas, se disponen a disputar un lugar en la jerarquía. (p. 59).

En un plano más general, hay evidencia empírica que sugiere que la educación constituye una inversión importante de las familias que puede observarse atendiendo a la alta proporción de niños, adolescentes y jóvenes que asisten a algún establecimiento escolar. De acuerdo con el relevamiento realizado por la Encuesta Nacional sobre la Estructura Social en el marco del Programa de Investigación sobe la Sociedad Argentina (ENES-PISAC 20142015), los porcentajes de asistencia a algún establecimiento educativo son del $98.3 \%$, para alumnos de entre los 5 y los 12 años; del $86.9 \%$ entre los 13 y los 18 años; del $37 \%$ entre los 19 y 26 años; y del $6.6 \%$ entre los de 27 años o más (Perona \& Schiavoni, 2018, p. 488). En Córdoba, también hemos observado una tendencia al incremento de asistencia a establecimientos escolares para los mismos grupos etarios entre 2003 y 2011 (Jiménez Zunino \& Giovine, 2017). El cambio más significativo se registra en la mayor participación 
de la clase baja en la escuela secundaria (la no asistencia disminuyó del 25\% al 11\% en ese periodo), que podría ser resultado de la aplicación de políticas ${ }^{7}$ como la $\mathrm{AUH}^{8}$ (Álvarez, 2013).

También, comparando los niveles educativos alcanzados por los referentes de hogar con los de la generación anterior, los primeros han aventajado en niveles educativos a sus padres, fruto de la expansión general del sistema educativo en las últimas cuatro décadas. En el relevamiento mencionado de ENES-PISAC 20142015, Kaplan y Piovani (2018) señalan que el 39.4\% de los jóvenes que asistía a la escuela secundaria durante la primera década del siglo XXI eran primera generación en el nivel, respecto a sus familias de origen, cuyos padres no habían logrado superar la escuela primaria. Estos datos proporcionan importantes indicios acerca de las estrategias de reproducción sobre los hijos, que involucra maniobras complejas de organización doméstica, prácticas de cuidado y vigilancia de progenitores, división del trabajo al interior de las familias y postergación de inserciones en el mercado de trabajo (generalmente femeninas), etc.

En suma, la hipótesis que subyace al escrito es la existencia de un modo de reproducción con un componente escolar que asume diferentes formatos en las clases sociales, teniendo en cuenta las trayectorias heterogéneas y desiguales en las que se traman las historias familiares. Partiendo de los estudios sobre estratificación social que utilizan metodología cualitativa (Bertaux \& Bertaux-Wiame, 2009; Bertaux \& Thompson, 2009) y cuantitativa (Courgeau, 1998; Peugny, 2012), intentamos reconstruir el proceso de transmisión de disposiciones respecto al capital cultural y

\footnotetext{
7 Este crecimiento de los años de escolarización se encuadra en una ampliación de la obligatoriedad (hasta los 18 años, después de la Ley de Educación Nacional (LEN 2006) y en el diseño de políticas públicas direccionadas a sostener la matrícula, asociadas al aumento de presupuesto (Jiménez Zunino \& Giovine, 2017).

8 Asignación Universal por Hijo para la Protección Social (AUH): se trata de una política de transferencia de ingresos implementada por Decreto 1602/2009 y que alcanza específicamente a población de hogares cuyos padres están desocupados o en condiciones de informalidad.
} 
la escuela en las familias de los entrevistados de diferentes clases sociales en Córdoba.

\section{Estrategia metodológica: Combinación de datos cuantitativos y cualitativos}

Nos apoyamos para este texto en materiales empíricos producidos en el marco de dos proyectos de investigación, uno colectivo y otro individual ${ }^{9}$. En primer lugar, desde una perspectiva estructural, disponemos del procesamiento estadístico, con técnicas multivariadas, de las bases de datos de la Encuesta Permanente de Hogares del Instituto Nacional de Estadísticas y Censos (en adelante, EPH-INDEC) correspondiente al año 2011 para el aglomerado Gran Córdoba. Esto dio lugar a un primer acercamiento objetivo de las posiciones del espacio social y a la multiplicidad de relaciones que constituyen los principales factores de desigualdad en el mismo (cuadro 1). El material cuantitativo ayudó a caracterizar las clases y fracciones de clase, y a orientar la selección muestral en la que se apoyó el trabajo cualitativo (cuadro 3, ver anexo). La selección muestral se realizó en base a la construcción de perfiles tipo, desde una serie de características que debían cumplir los casos seleccionados, fruto de la etapa estadística.

El trabajo cualitativo consta de 43 entrevistas en profundidad a referentes de hogar posicionados en las distintas clases y fracciones de clase del espacio social cordobés ${ }^{10}$. El mismo se realizó entre julio de 2014 y diciembre de 2015. Se aplicaron entrevistas en profundidad a una selección de perfiles de clase y fracciones

Los resultados de este artículo se desprenden de un proyecto de investigación colectivo: "Reproducción social en el Gran Córdoba: estrategias familiares y dinámicas" recientes (Investigadora responsable: Alicia Beatriz Gutiérrez, PICT 2016-2018), y otro individual: “La transformación de las clases sociales en Córdoba. Estrategias de reproducción social en las trayectorias de las clases medias".

10 La cantidad de entrevistas estuvo definida por criterios de saturación de cada uno de los perfiles de clase y fracción de clase. La cantidad de entrevistas que se tomaron para cada clase - ver cuadro 3 en anexo - representa su porcentaje en el total. 
de clases (tipología) construidas en la etapa cuantitativa. Las entrevistas se realizaron a referentes de hogar, excepto en 3 casos, en los que se aplicó al cónyuge por no ser posible coordinar con el principal sostén de hogar, y duraron en torno a 2 o 3 horas. En todos los casos, en los cuestionarios se solicitaba información sobre ambos miembros de la pareja, sobre sus antecesores (padres y suegros), laterales (hermanos y cuñados) y descendientes (hijos), permitiendo de este modo reconstruir las trayectorias de gran parte de los miembros de la familia, tanto antecesores (padre y madre) como sucesores y paralelos (hermanos y cuñados). Con esta información, se construyó una aproximación al escenario de socialización y a la trama de posibilidades, inclinaciones, orientaciones y elecciones en las familias en diferentes momentos de su devenir. A partir de este material, accedimos a distintas dimensiones de sus apuestas, modulaciones, trayectorias y sentidos vividos sobre sus estrategias de reproducción social. Desde las posiciones actuales de los entrevistados, reconstruimos trayectorias de desclasamiento (ascendente o descendente) o sostenimiento en la posición de clase cuando se observa la dimensión intergeneracional, conectando los momentos de las familias y sus ciclos vitales con los diferentes momentos históricos de la estructura social.

El esquema interpretativo que hemos seguido para el análisis de las trayectorias intergeneracionales de las clases es fruto de una elaboración que se apoya en las aportaciones de Bertaux (1995), y Bertaux y Bertaux-Wiame (2009), ya utilizado en investigaciones anteriores (Jiménez Zunino, 2011, 2015). El esquema está conformado por tres vectores: i) el capital de origen y la acumulación originaria al interior de sus familias; ii) el modo en que los sujetos han sido delineados desde las familias para sus inserciones sociales (especialmente, laborales y educativas) de acuerdo con los capitales a reproducir; y iii) la relación entre las estrategias de reproducción social de las familias y los diferentes momentos históricos.

Por el volumen de datos obtenidos, y la dificultad para su sistematización, aquí mostramos solo un primer esbozo del análisis, que pretende ser continuado en futuros escritos. El modo 
de tratamiento de los relatos producidos en las entrevistas no se corresponde, en este texto, con la exposición de verbatims, pues la cantidad de voces e historias entramadas desborda la capacidad contenedora de un artículo. Hemos optado por sintetizar y agrupar los rasgos comunes que aproximan a unos sujetos, diferenciándolos de otros en el trazado de sus trayectorias.

Este artículo se plantea también como una instancia de reflexión sobre algunas premisas epistemológicas del análisis con datos cualitativos - siempre que se encuentren apoyados en una selección muestral estadística- para abordar las formas de reproducción intergeneracional de las familias, la desigualdad social y la estratificación. En primer lugar, se fundamenta el hecho a partir de la posición de referente del hogar para reconstruir las trayectorias familiares desde una economía de esfuerzos que posibilita ganar en productividad de datos (Bertaux, 1995). En segundo lugar, se defiende la validez hermenéutica de los datos de los entrevistados, en tanto son fuente tanto de información como de significados (Bertaux, 2005). Por último, se suscribe el postulado de Lahire (2006) acerca de arriesgar la interpretación, dentro de un marco analítico que permita conectar los datos vertidos en un relato biográfico con los datos de carácter estructural (obtenidos por procedimientos estadísticos y por estudios históricos y sociológicos que enmarcan la interpretación).

\section{Resultados. Las clases sociales cordobesas y sus transmisiones intergeneracionales}

Las clases sociales cordobesas están caracterizadas a nivel estadístico desde el procesamiento de los datos de la EPH 2003 y 2011 de INDEC ${ }^{11}$. En el cuadro 1 se expresan las modalidades de

11 Se utilizaron métodos multivariados (análisis de correspondencias múltiples) y técnicas de clasificación (clasificación jerárquica ascendente) para la construcción de cuatro clases y siete fracciones de clase. Un desarrollo de los procedimientos utilizados y los resultados detallados pueden consultarse en Gutiérrez y Mansilla (2015). 
las variables que más están asociadas a cada uno de los grupos, elementos que dan sustento a algunas de las interpretaciones realizadas en el trabajo cualitativo.

Cuadro 1

Características de las clases del espacio social de Gran Córdoba (2011)

\begin{tabular}{|c|c|c|c|c|}
\hline \multirow[b]{2}{*}{ Variables } & \multicolumn{4}{|c|}{ Clases sociales } \\
\hline & $\begin{array}{c}\text { Clase media } \\
\text { alta }(17 \%)\end{array}$ & $\begin{array}{l}\text { Clase media } \\
\quad(29 \%)\end{array}$ & $\begin{array}{l}\text { Clase traba- } \\
\text { jadora }(35 \%)\end{array}$ & $\begin{array}{c}\text { Precariado } \\
(20 \%)\end{array}$ \\
\hline Ingresos & Decil 10 & Deciles 7-9 & $\begin{array}{l}\text { Deciles 3-5 } \\
\left(\mathrm{IPCF}^{*}\right) \\
\text { Deciles 5-8 } \\
\left(\text { ITI RH }{ }^{* *}\right)\end{array}$ & Decil 1 \\
\hline $\begin{array}{l}\text { Calificación } \\
\text { ocupacional }\end{array}$ & $\begin{array}{l}\text { Profesional- } \\
\text { directivos }\end{array}$ & Técnica & Operativa & No calificada \\
\hline $\begin{array}{l}\text { Nivel educa- } \\
\text { tivo }\end{array}$ & $\begin{array}{l}\text { Universitario } \\
\text { completo }\end{array}$ & $\begin{array}{l}\text { Universitario } \\
\text { completo e } \\
\text { incompleto }\end{array}$ & $\begin{array}{l}\text { Secundario } \\
\text { incompleto }\end{array}$ & $\begin{array}{l}\text { Primario } \\
\text { incompleto }\end{array}$ \\
\hline $\begin{array}{l}\text { Sexo /edad } \\
\text { referente }\end{array}$ & Masculino & $\begin{array}{l}\text { Femenino }(\leq \\
34)\end{array}$ & Masculino & $\begin{array}{l}\text { Femenino }(50 \\
\text { a } 64)\end{array}$ \\
\hline $\begin{array}{l}\text { Rama /jerar- } \\
\text { quía }\end{array}$ & $\begin{array}{l}\text { Servicios } \\
\text { privados } \\
\text { (patrones) y } \\
\text { directivos de } \\
\text { Estado }\end{array}$ & $\begin{array}{l}\text { Servicios } \\
\text { sociales } \\
\text { (educación, } \\
\text { gestión ad- } \\
\text { ministrativa } \\
\text { y salud) }\end{array}$ & $\begin{array}{l}\text { Industria, } \\
\text { transporte, } \\
\text { construcción } \\
\text { y cuentapro- } \\
\text { pismo }\end{array}$ & $\begin{array}{l}\text { Servicio } \\
\text { doméstico, } \\
\text { construcción } \\
\text { y cuentapro- } \\
\text { pismo }\end{array}$ \\
\hline $\begin{array}{l}\text { Tipo de } \\
\text { hogar }\end{array}$ & & Unipersonal & $\begin{array}{l}\text { Numerosos } \\
\text { (+ } 6 \text { miem- } \\
\text { bros) }\end{array}$ & $\begin{array}{l}\text { Numerosos } \\
\text { (+ } 6 \text { miem- } \\
\text { bros) }\end{array}$ \\
\hline
\end{tabular}

Nota: ${ }^{*}$ Ingreso per cápita familiar. ${ }^{* *}$ Ingreso total individual del referente dehogar. Elaboración propia en base a trabajo colectivo: EPH (2011) ( $3^{\circ}$ trimestre).

A continuación, desarrollamos una interpretación de las clases sociales, considerando sus capitales originarios (en sentido relativo) y los recursos movilizados para elaborar sus estrategias educativas en la reproducción social intergeneracional. La generación anterior a la del entrevistado (ego) será nombrada "antecesores", la posterior como "sucesores". 


\section{Precariado}

Desde una caracterización elaborada a partir del procesamiento estadístico, esta clase conformaba el 20\% del espacio social de Gran Córdoba en 2011, y contaba con asociaciones fuertes con ingresos en el primer decil, sin calificación laboral, en ocupaciones como el servicio doméstico, el cuentapropismo y la construcción (sin antigüedad laboral, ni cobertura médica). El nivel educativo más asociado es hasta primario completo. El procedimiento de clasificación (clasificación jerárquica ascendente) particiona dos fracciones para esta clase que denotan diferentes configuraciones familiares: una fracción feminizada, cuyo referente de hogar se ocupa en el servicio doméstico (mujeres divorciadas o viudas) y otra fracción masculina, con referente cuentapropista, calificación operativa y cuyos hogares son muy numerosos.

Siguiendo la valiosa línea de análisis de Gutiérrez (2005), optamos en este análisis por considerar a la clase baja o precariado desde sus recursos relativos antes que desde sus carencias. En esa dirección, analizamos las trayectorias intergeneracionales de estas familias que, posicionadas en la parte más baja del espacio social - al momento de la captura de los datos-, elaboran estrategias de reproducción educativas hacia sus hijos.

De acuerdo con el material cualitativo (9 entrevistas), los orígenes sociales en la generación anterior al entrevistado están ubicados tanto en zonas rurales (migración rural-urbana desde los años 1960) como en zonas urbanas. Si atendemos al capital de origen, en algunos casos se observan en la generación de los antecesores algunas inserciones en el Estado (con ocupaciones de: radiotelegrafista de Correo Central, militares, vialidad provincial, administrativo en municipalidad, etc.). Si bien se trata de puestos inferiores de la administración, estos proporcionaban ciertas garantías de integración social desde relaciones salariales en contextos de expansión del Estado de bienestar. Estas inserciones no requerían, en ese momento, más que de titulaciones de escolari- 
zación primaria, en ocasiones incompleta, y se trataba en muchos casos de trabajos con estabilidad y jubilación garantizada.

En algunos casos encontramos en la muestra padres con secundario completo, siendo que la generación de ego (entrevistado) apenas contaba con primario incompleto. Aquí, una serie de acontecimientos que emergen de los relatos pueden explicar cierto desclasamiento: familias numerosas, fallecimiento del principal proveedor, enfermedades y adicciones de algunos de los hijos (que aumentan las tasas de dependencia) (Perona y Schiavoni, 2018). Esto sugiere que captar a las personas entrevistadas en el precariado como posición actual corresponde con un momento de una trayectoria intergeneracional de desclasamiento descendente.

En otros casos, los antecesores tienen primario incompleto. Sin embargo, este rasgo de la generación de los padres es compartido con otras clases sociales, como veremos, lo que puede explicarse por el efecto cohorte (Elder, 1994) de las edades de los padres en un momento histórico en el que no estaba tan masificado el acceso a la educación (Torrado, 2003). Sin embargo, esto hace pensar también en la gran dispersión de las trayectorias sociales desde orígenes que podrían parecer similares si atendemos solo al capital cultural o al lugar de origen (como puede ser la zona rural).

Respecto a las inserciones que se relacionan con el origen rural (previo a migrar hacia la ciudad la persona entrevistada), suele tener asidero en la tenencia de algún terreno en los pueblos de origen. Es el caso de Osmar ${ }^{12}$, quien había emigrado a la ciudad a los 25 años junto a dos de sus nueve hermanos para trabajar en la construcción, mientras que en el campo quedaron sus padres y demás hermanos. Estas migraciones internas parciales suponen gran vinculación con la zona rural: viajes periódicos para ver a la

12 Se referencian todos los casos con nombres de fantasía. Se sugiere seguir la lectura con el cuadro 2 . 
familia, persistencia de parte de los hermanos realizando labores en el campo, desigual acceso a los recursos de la ciudad.

Por último, encontramos actividades vinculadas a la artesanía y el comercio en la generación de los antecesores, que se han transformado gracias a la aplicación de capital cultural con estrategias de marketing desde las nuevas tecnologías de la información para la venta. Es el caso de Rafael, carpintero de 29 años que usa Facebook para vender sus productos, ayudado por su esposa. Ambos cuentan con secundario completo. En casos como éstos $^{13}$, se da una aplicación de recursos educativos en la elaboración de las estrategias de venta que se amplifican gracias al uso de las redes sociales.

Respecto a las inversiones escolares hacia los hijos, vemos ciertos rasgos comunes en esta clase, orientados a sostener estrategias de reproducción con un componente escolar en el marco de sus posibilidades. Evidentemente, puede tratarse de una estrategia discursiva presentada en el momento de la entrevista (por tratarse de un discurso legítimo, esgrimido ante el entrevistador universitario). Sin embargo, se vio reforzada también por las prácticas relatadas ${ }^{14}$ (elección de escuelas más lejanas al domicilio, por considerarlas mejores; cambiar a hijos de escuelas percibidas como problemáticas: bullying, malos tratos, compañías indeseables, etc.). También, algunas entrevistadas de esta clase relataron sostener cuidados respecto a los contenidos que los niños ven en la TV y control de horas de exposición.

13 La cónyuge del referente de hogar tiene estudios de profesorado de matemáticas incompletos, y se encuentra cursando enfermería mientras trabaja en servicio doméstico.

14 Extrajimos de esto una consecuencia metodológica. Es posible, en una entrevista en profundidad, visualizar prácticas más allá del discurso textual, haciendo interpretación cruzada del texto. Por ejemplo, el caso de Danilo, quien parece no dar importancia a los estudios (desconoce informaciones precisas sobre la escolarización de los hijos), pero relata prácticas (influidas posiblemente por su esposa) que indican otra cosa: cambios de colegios, búsqueda de contactos para buscar banco, sostenimiento y apoyo para realización de actividades extraescolares (como el deporte). 
Sin embargo, en hogares muy numerosos, prima el abandono de la escuela secundaria en los hijos mayores, relatada de tal modo que se articula con el momento en que comienzan a trabajar. En este tipo de hogares parece que los mayores esfuerzos se concentran en las hijas más pequeñas (en las entrevistas realizadas, mayormente mujeres), quienes en ocasiones son enviadas a colegios privados de cuota baja. Es el caso de Guillermo: de sus seis hijos, los cinco mayores dejaron los estudios antes de finalizar la secundaria — desde el plano intergeneracional, lograron así todo más años de escolarización que Guillermo y su esposa. La hija más pequeña (13 años), sin embargo, es enviada a un colegio confesional, de cuota cero, para ser compatible con el cobro de la Asignación Universal por Hijo. Esto puede relacionarse con los propios ciclos de las familias, que suelen tender hacia una estabilización a medida que se afianza el grupo familiar.

Dado que las parejas no son todas homogámicas en términos de capital cultural, el empuje de alguno de los miembros con más capital cultural hace que las inversiones sobre los hijos sean más sostenidas. Es el caso de la exesposa de Arturo, quien terminó el secundario en un colegio nocturno y se formó como enfermera, además de tener un padre con terciario de profesorado incompleto e insiste en enviar a los hijos a un colegio privado del que tenían muy buenas referencias.

Por último, hallamos en esta clase otras formas de invertir en capital cultural: es el caso de quienes se dedican a la música o al deporte de manera aficionada o como un complemento de las actividades económicas. A un entrevistado, Darío - secundario incompleto, trabaja de jardinero-, el padre, que era empleado municipal, le regaló un piano y equipos de música, siendo él adolescente, y ahora es cantante de un grupo de música tropical. Otro entrevistado, Guillermo, quien trabaja en la construcción con varios de sus hijos, se declara manager del grupo de folclore de sus hijos, cuya dedicación alternan con los trabajos en la construcción. 


\section{Cuadro 2}

Características de los entrevistados pertenecientes a las clases y fracciones de clase de Gran Córdoba

\begin{tabular}{|c|c|c|c|}
\hline Clase & Fracción & Entrevistado & Descripción \\
\hline \multirow{8}{*}{ 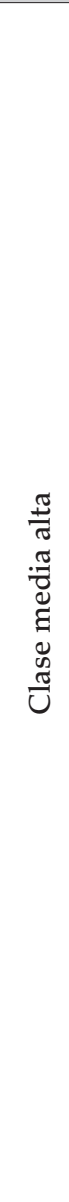 } & \multirow{6}{*}{ 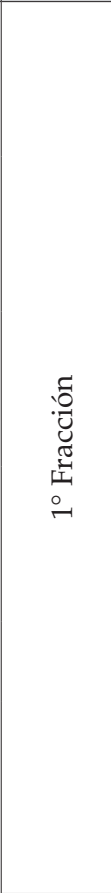 } & Ricardo & $\begin{array}{l}\text { Investigador de CONICET, } 61 \text { años. Universita- } \\
\text { rio y doctorado. Referente de hogar y cónyuge } \\
\text { (universitario completo). Dos hijos emancipados } \\
\text { (31 y 28). }\end{array}$ \\
\hline & & Silvana & $\begin{array}{l}\text { Camarista, } 60 \text { años. Universitario y posgrado. Re- } \\
\text { ferente de hogar, cónyuge jubilado (universitario } \\
\text { completo) y dos hijos ( } 32 \text { y 30). Hijo de } 34 \text { eman- } \\
\text { cipado. }\end{array}$ \\
\hline & & Federico & $\begin{array}{l}\text { Director institución educativa y docente, } 52 \text { años. } \\
\text { Universitario y posgrado. Referente de hogar de } \\
\text { cuatro miembros: cónyuge ( } 52 \text {, universitario com- } \\
\text { pleto y posgrado) y dos hijos ( } 20 \text { y } 14) \text {. }\end{array}$ \\
\hline & & José & $\begin{array}{l}\text { Prosecretario de justicia, } 46 \text { años. Universitario y } \\
\text { posgrado. Referente de hogar de cinco miembros: } \\
\text { cónyuge ( } 44 \text {, universitario completo) y tres hijas (14, } \\
11 \text { y 8) }\end{array}$ \\
\hline & & Andrea & $\begin{array}{l}\text { Directora instituto terciario, } 58 \text { años. Universitario y } \\
\text { posgrado. Referente de hogar unipersonal. }\end{array}$ \\
\hline & & Magdalena & $\begin{array}{l}\text { Asesora técnica de Agencia de Promoción de Em- } \\
\text { pleo, } 57 \text { años. Universitario y posgrado. Referente de } \\
\text { hogar unipersonal y sostén de hogar de } 3 \text { hijos (30, } \\
28 \text { y 26). Hijo mayor emancipado (32) residiendo en } \\
\text { China. Separada (exmarido: universitario completo). }\end{array}$ \\
\hline & \multirow{2}{*}{ 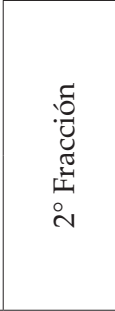 } & Mariano & $\begin{array}{l}\text { Dueño de consultora, } 55 \text { años. Universitario y pos- } \\
\text { grado. Referente de hogar de dos miembros. Cón- } \\
\text { yuge (universitario completo). Segundo matrimo- } \\
\text { nio. }\end{array}$ \\
\hline & & Antonio & $\begin{array}{l}\text { Dueño empresa transportes, } 65 \text { años. Universitario } \\
\text { incompleto. Referente de hogar de tres miembros: } \\
\text { cónyuge ( } 53 \text {, universitario completo) e hijo (11). Se- } \\
\text { gundo matrimonio. }\end{array}$ \\
\hline
\end{tabular}


Modo de reproducción escolar en las clases sociales cordobesas. Un análisis desde las transmisiones intergeneracionales - Jiménez

\begin{tabular}{|c|c|c|c|}
\hline & & Lucía & $\begin{array}{l}\text { Médica en hospitales públicos y privados, } 30 \text { años. } \\
\text { Universitario y posgrado. Referente de hogar uni- } \\
\text { personal. Separada (exmarido: universitario incom- } \\
\text { pleto) }\end{array}$ \\
\hline & & Viviana & $\begin{array}{l}\text { Empleada pública, } 43 \text { años. Universitario y posgra- } \\
\text { do. Referente de hogar unipersonal. }\end{array}$ \\
\hline & 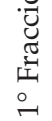 & Luisa & $\begin{array}{l}\text { Médica en hospital público, } 54 \text { años. Universitario } \\
\text { completo. Referente de hogar: dos hijas ( } 20 \text { y 18). } \\
\text { Separada (exmarido: secundario incompleto). }\end{array}$ \\
\hline & & Sandra & $\begin{array}{l}\text { Docente primario y preceptora, } 49 \text { años. Terciario } \\
\text { completo. Referente de hogar: dos hijas ( } 26 \text { y } 24 \text { ). } \\
\text { Separada (exmarido: secundario completo) }\end{array}$ \\
\hline & & Adriana & $\begin{array}{l}\text { Vicedirectora escuela secundaria, } 57 \text { años. Univer- } \\
\text { sitario completo. Referente de hogar unipersonal. }\end{array}$ \\
\hline & & Gerardo & $\begin{array}{l}\text { Programador de empresa informática, } 41 \text { años. Uni- } \\
\text { versitario incompleto. Referente de hogar. Cónyuge } \\
\text { masculino ( } 58 \text {, universitario incompleto). }\end{array}$ \\
\hline 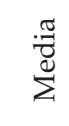 & & Nahuel & $\begin{array}{l}\text { Empleado administrativo empresa gas, } 25 \text { años. } \\
\text { Universitario incompleto. Referente de hogar uni- } \\
\text { personal. }\end{array}$ \\
\hline & & Iris & $\begin{array}{l}\text { Empleada pública, } 36 \text { años. Universitario incomple- } \\
\text { to. Cónyuge de hogar de dos miembros (referente } \\
\text { 32, universitario completo y doctorado). }\end{array}$ \\
\hline & :0ّ & Jorgelina & $\begin{array}{l}\text { Empleada empresa bebidas, } 26 \text { años. Universitario } \\
\text { incompleto, cónyuge de hogar de dos miembros (re- } \\
\text { ferente } 26 \text {, universitario completo). }\end{array}$ \\
\hline & $\stackrel{\text { I }}{\stackrel{1}{\sim}}$ & Flavio & $\begin{array}{l}\text { Gerente empresa familiar, } 32 \text { años. Universitario } \\
\text { incompleto. Referente de hogar de dos miembros: } \\
\text { cónyuge ( } 31 \text {, universitario completo). }\end{array}$ \\
\hline & & Pedro & $\begin{array}{l}\text { Preceptor, } 32 \text { años. Terciario incompleto. Referente } \\
\text { de hogar unipersonal }\end{array}$ \\
\hline & & Dante & $\begin{array}{l}\text { Empleado, } 32 \text { años. Universitario incompleto. Refe- } \\
\text { rente de hogar unipersonal }\end{array}$ \\
\hline & & Enrique & $\begin{array}{l}\text { Vendedor inmobiliario y martillero, } 33 \text { años. Tercia- } \\
\text { rio completo. Referente de hogar de } 2-3 \text { miembros: } \\
\text { cónyuge ( } 32 \text {, universitario completo) e hijo ( } 6 \text { años, } \\
\text { custodia compartida). Segunda unión. }\end{array}$ \\
\hline
\end{tabular}




\begin{tabular}{|c|c|c|c|}
\hline & & Milo & $\begin{array}{l}\text { Taxista, } 61 \text { años. Secundario completo. Referente de } \\
\text { hogar de dos miembros: cónyuge }(58 \text {, secundario } \\
\text { completo) y tres hijos emancipados }(34,32 \text { y } 31) \text {. }\end{array}$ \\
\hline & & Laura & $\begin{array}{l}\text { Panadera, } 64 \text { años. Secundario completo más cursos. } \\
\text { Referente de hogar de dos miembros: cónyuge (66, se- } \\
\text { cundario completo). Dos hijos emancipados ( } 36 \text { y } 33 \text { ). }\end{array}$ \\
\hline & :0 & Alberto & $\begin{array}{l}\text { Camionero, } 55 \text { años. Secundario incompleto. Refe- } \\
\text { rente de hogar de tres miembros: cónyuge ( } 55 \text {, se- } \\
\text { cundario completo más cursos) e hijo (27). Dos hijos } \\
\text { más, emancipados ( } 32 \text { y } 29 \text { ). }\end{array}$ \\
\hline & 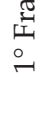 & Oscar & $\begin{array}{l}\text { Jardinero, } 64 \text { años. Secundario incompleto. Referen- } \\
\text { te de hogar de dos miembros (cónyuge, primario } \\
\text { completo). } 5 \text { hijos emancipados. }\end{array}$ \\
\hline & & Eduardo & $\begin{array}{l}\text { Mecánico autónomo, } 60 \text { años. Secundario incom- } \\
\text { pleto. Referente de hogar de tres miembros: cónyu- } \\
\text { ge ( } 49 \text {, secundario completo) e hija (10). Segundo } \\
\text { matrimonio. }\end{array}$ \\
\hline & & Iván & $\begin{array}{l}\text { Taxista, } 66 \text { años. Secundario completo. Referente de } \\
\text { hogar unipersonal. Separado con } 5 \text { hijos emancipa- } \\
\text { dos. Exesposa: secundario completo (maestra). }\end{array}$ \\
\hline $\begin{array}{l}\frac{\pi}{0} \\
\frac{0}{0} \\
.\end{array}$ & & Carina & $\begin{array}{l}\text { Operaria fábrica autopartes, } 43 \text { años. Universitario } \\
\text { incompleto. Referente de hogar (tres hijas: 19, 12, 11). } \\
\text { Viuda (cónyuge fallecido: secundario incompleto). }\end{array}$ \\
\hline 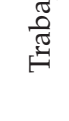 & & Matías & $\begin{array}{l}\text { Empleado en una sandwichería, } 43 \text { años. Universi- } \\
\text { tario incompleto. Referente de hogar. Cónyuge ( } 37 \text {, } \\
\text { secundario completo más cursos) e hijos ( } 16,8 \text { y 5). }\end{array}$ \\
\hline & & Marina & $\begin{array}{l}\text { Ama de casa, } 26 \text { años. Universitario incompleto. } \\
\text { Cónyuge de hogar con referente de } 34 \text { años, tercia- } \\
\text { rio incompleto, empleado fábrica de cerámicos. Dos } \\
\text { hijos ( } 2 \text { años y } 2 \text { meses). }\end{array}$ \\
\hline & 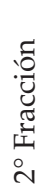 & Fermín & $\begin{array}{l}\text { Operario fábrica automotriz, } 43 \text { años. Secundario } \\
\text { completo. Referente de hogar: cónyuge ( } 44 \text {, secun- } \\
\text { dario completo más cursos), dos hijos ( } 11 \text { y } 9 \text {, de } \\
\text { ella). Segundo matrimonio. Dos hijas del primero } \\
\text { no convivientes ( } 25 \text { y } 23) \text {. }\end{array}$ \\
\hline & & Adam & $\begin{array}{l}\text { Chofer de empresa transporte urbano, } 31 \text { años. Ter- } \\
\text { ciario incompleto. Referente de hogar. Cónyuge ( } 32 \text {, } \\
\text { terciario completo) y } 3 \text { hijos ( } 5 \text { y mellizos de } 1)\end{array}$ \\
\hline & & Edmundo & $\begin{array}{l}\text { Chofer de colectivos interurbanos, } 54 \text { años. Secunda- } \\
\text { rio incompleto. Referente de hogar. Dos hijos ( } 11 \text { y 9). } \\
\text { Separado, custodia compartida. Exesposa: secunda- } \\
\text { rio completo más cursos. }\end{array}$ \\
\hline & & Norberto & $\begin{array}{l}\text { Operario empresa automotriz, } 47 \text { años. Primario } \\
\text { completo. Referente de hogar: cónyuge ( } 43 \text {, secun- } \\
\text { dario incompleto) y tres hijos }(17,10 \text { y } 3) \text {. Hija ma- } \\
\text { yor emancipada (27). }\end{array}$ \\
\hline
\end{tabular}




\begin{tabular}{|c|c|c|c|}
\hline & \multirow{3}{*}{ 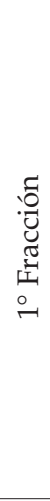 } & Mirna & $\begin{array}{l}\text { Costurera, } 62 \text { años. Primaria completa. Referente de } \\
\text { hogar: hija (36) y nieta (4). Viuda (marido fallecido, } \\
\text { primario completo) y otro hijo emancipado (32). }\end{array}$ \\
\hline \multirow{8}{*}{ 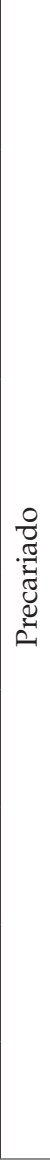 } & & Carolina & $\begin{array}{l}\text { Empleada doméstica, } 41 \text { años. Secundario incom- } \\
\text { pleto. Referente de hogar de tres miembros: dos } \\
\text { hijos }(15 \text { y 11). Separada. Exmarido: secundario in- } \\
\text { completo }\end{array}$ \\
\hline & & Noemí & $\begin{array}{l}\text { Servicio doméstico y de cuidados, } 69 \text { años. Primario } \\
\text { incompleto. Referente de hogar de nueve miem- } \\
\text { bros: dos hermanas ( } 82 \text { y } 74) \text {, una hija (30) con tres } \\
\text { nietos }(12,8 \text { y 4), un hijo (26) con su pareja (25) y } \\
\text { un nieto a su cargo (13). Viuda (marido fallecido } \\
\text { secundario completo). }\end{array}$ \\
\hline & \multirow{6}{*}{ 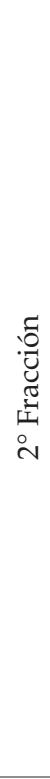 } & Arturo & $\begin{array}{l}\text { Albañil, } 27 \text { años. Secundaria incompleta. Referente } \\
\text { de hogar extenso (varios hogares en la vivienda) } \\
\text { abuela (85), padre (66), madre (64), y } 3 \text { hijos ( } 7,5 \\
\text { y 3) en custodia compartida. Separado. Exesposa } \\
\text { terciario incompleto. }\end{array}$ \\
\hline & & Rafael & $\begin{array}{l}\text { Carpintero, } 29 \text { años. Secundario completo. Referen- } \\
\text { te de hogar. Cónyuge ( } 25 \text {, terciario incompleto) y } \\
\text { dos hijos (6 y } 3) \text {. }\end{array}$ \\
\hline & & Osmar & $\begin{array}{l}\text { Albañil, } 44 \text { años. Primaria completa. Referente de } \\
\text { hogar unipersonal. Separado con } 5 \text { hijos }(17,15,12 \\
\text { 10,3). Exesposa: primaria incompleta. }\end{array}$ \\
\hline & & Darío & $\begin{array}{l}\text { Jardinero, } 34 \text { años. Secundario incompleto. Referen- } \\
\text { te de hogar ( } 3 \text { hijos de 11, } 8 \text { y } 7 \text { ). Separado, custodia } \\
\text { compartida. Exesposa: secundaria incompleta. }\end{array}$ \\
\hline & & Guillermo & $\begin{array}{l}\text { Construcción, } 51 \text { años. Primaria completa. Referen- } \\
\text { te de hogar. Cónyuge ( } 46 \text {, primaria incompleta), } 2 \\
\text { hijos ( } 28 \text { y 13) y } 2 \text { nietos ( } 10 \text { y 9). }\end{array}$ \\
\hline & & Danilo & $\begin{array}{l}\text { Pintor, } 55 \text { años. Secundario completo. Referente de } \\
\text { hogar. Cónyuge ( } 43 \text {, secundaria completa) y cuatro } \\
\text { hijos }(18,17,11 \text { y } 10) \text {. }\end{array}$ \\
\hline
\end{tabular}

Nota: Elaboración propia

\section{Clase trabajadora}

Compuesta por aproximadamente el 35\% de los hogares del espacio social, se definen por tener ingresos medios y bajos $\left(3^{\circ}\right.$ a $5^{\circ}$ decil, si se toma el ingreso per cápita familiar, pero llegando hasta el $8^{\circ}$ decil, si se considera el ingreso de la ocupación principal del referente de hogar). Sus referentes se insertan en las 
ramas de la construcción, la industria, el transporte y la logística, en condición de autónomos y en establecimientos pequeños del sector privado. La clase se caracteriza, además, por una fuerte asociación a situaciones conyugales (unidos o casados), a configuraciones familiares con 4 o más miembros y una alta presencia de menores de 10 años (ver cuadro 1). Esto se relaciona con las altas tasas de dependencia identificadas por Perona y Schiavoni (2018), características en los hogares conformados por obreros (Torrado, 2003). El capital escolar de sus referentes tiende a ser relativamente bajo (el nivel educativo va de primario incompleto a secundario incompleto).

Desde el material cualitativo (13 entrevistas), detectamos que en esta clase hay un fuerte componente obrero que se inserta en fábricas autopartistas en la generación de los antecesores o en las etapas iniciales de las trayectorias de los entrevistados (dependiendo de la edad). Otra rama que aparece con fuerza es la de transporte (camiones, colectivos y taxis), no solo en la generación de los entrevistados (por el diseño muestral, se buscaba esa inserción), sino en la generación anterior, aspecto que se hace visible a través de las entrevistas en profundidad. Así, parte de los entrevistados que actualmente son choferes de camiones han comenzado a ejercer esta actividad con sus padres. Los hijos de camioneros "heredan" ese trabajo (que supone una fuerte inversión económica en los camiones en el momento del gran auge del transporte por carretera cuando cierran los ferrocarriles durante la década de 1990). En los casos analizados (Alberto y Edmundo), los entrevistados dejaron el secundario sin terminar (tercero y cuarto año, respectivamente) en la época en que el padre de cada uno compró el camión. De ellos dos, solo Alberto trabaja actualmente como chofer, pero por cuenta ajena en una empresa.

Respecto a las inserciones en fábricas vinculadas a la industria automotriz y metalmecánica, hay quienes trabajaron durante muchos años y luego fueron despedidos en ciclos de retraimien- 
to, virando hacia actividades más informales (conducción de taxi propio, en el caso de Milo, y jardinería y pintura en el de Oscar).

Estos trabajos masculinos (con uso extensivo del tiempo en el espacio laboral) se complementan con una sostenida presencia en el hogar de mujeres amas de casa o trabajadoras en servicio doméstico ocasionales, pues la intensidad horaria de referentes (turnos rotativos en fábricas, régimen de transportistas, etc.) dificultan la disponibilidad de tiempo para la inserción laboral de ellas. Uno de los casos, Lola — esposa de Alberto (camionero) - tiene secundario completo (en escuela privada confesional) y relata la constante vigilancia que tuvo sobre el rendimiento escolar de los hijos: búsqueda permanente de la escuela adecuada y control sobre la justicia de las notas de calificación. Es interesante destacar que el hijo mayor (Lisandro) se encuentra en Brasil estudiando un doctorado en matemáticas, con beca y buen puntaje ${ }^{15}$. Los otros dos hijos no han finalizado estudios superiores. En un momento de la entrevista nos comenta su madre: "Álvaro es tan inteligente como Lisandro, o más, pero es un vago terrible". Álvaro emigró a Nueva Zelanda, donde trabajó en una fábrica de papas fritas. Al momento de la entrevista vivía con sus padres y al parecer estaba retomando los estudios de profesorado en matemática "como su hermano". Los padres reconocen que las comparaciones pueden pesar en el hijo pequeño al tener tan buen desempeño el mayor. Es interesante esta cuestión, porque no parece haber esta comparación respecto a la hija mujer (se enfatizan las diferencias entre los dos hermanos varones, entre los paralelismos de las carreras escogidas, las diferentes aficiones a las salidas, etc.).

Uno de los fenómenos estructurales a considerar en estos casos es el engrosamiento y expansión del sistema universitario en los últimos 15 años. En Argentina, la matrícula universitaria creció un 22\% entre 2001 y 2011, se crearon nuevas universidades

\footnotetext{
15 Aquí señalamos nuevamente el papel de las políticas sociales y la ampliación de becas durante la primera quincena del siglo XXI que generaron el acceso a estudios de posgrado desde sectores populares (Ruta, 2015).
} 
en diferentes regiones del país (muchas de ellas alejadas de los polos culturales dominantes) y una importante masa de personas que son primera generación de estudiantes universitarios accedió (Ruta, 2015). En el contexto regional, Argentina es uno de los países con mayor acceso a la universidad por parte de personas provenientes de hogares de menores recursos, con una tasa de participación del quintil más pobre equivalente al 20\%, según lo estimado por Brunner (2011).

En tanto, los obreros fabriles en gran parte de su trayectoria (Oscar, Norberto, Fermín, Carina, Milo), están lejos de alguna desorientación sobre la importancia de las inversiones escolares hacia los descendientes (Beaud y Pialoux, 2014). Casi todos los entrevistados hacían esfuerzos enormes para mejorar las chances educativas de sus hijos: enviarlos a colegios privados prestigiosos (Norberto, Milo) o preparar a las hijas para rendir un examen de ingreso en un colegio público prestigioso (Carina). Otros, en cambio, esgrimían una mezcla de argumentos entre no querer estudiar y tener que trabajar para explicar el abandono de la escuela de los hijos, como es el caso de Oscar: de sus cinco hijos, que tienen entre 40 y 23 años, solo una intenta terminar el secundario para adultos.

\section{Clase media}

La composición de esta clase sería en 2011 de un 29\%, siendo relevante en su configuración el tipo de hogares (pequeños o unipersonales), cuyos referentes son jóvenes y con ingresos fuertemente asociados a niveles medios y altos (ingreso per cápita familiar ubicado entre el $7^{\circ}$ y el $9^{\circ}$ decil). Las ocupaciones de los jefes de hogar se asocian a puestos de técnicos o profesionales, en la condición de empleados asalariados y, en menor medida, de jefes, en las ramas de educación, salud y gestión jurídico-administrativa. Sus inserciones en el mercado de trabajo se vinculan al sector estatal, en establecimientos medianos (de 6 a 40 personas) con cobertura médica, social y laboral (Gutiérrez y Mansilla, 2015). 
Al seleccionarse las personas de la muestra por su posición actual (de clase media, 13 entrevistas), estas son más homogéneas que sus orígenes sociales. Algunos tienen al menos uno de sus padres con estudios universitarios completos o incompletos que se han desempeñado como asalariados o autónomos (propietarios de pequeñas y medianas empresas también). Otro grupo es de orígenes sociales más modestos, cuyos padres tenían secundario completo o primario incompleto, en ocupaciones como maestra, empleados administrativos y de comercio, fuerzas de seguridad, etc. Es posible inferir, por lo tanto, un ascenso social, especialmente en entrevistados mayores de 50 años, correspondiente con otro momento de la estructura social, más permeable a la movilidad social ascendente que confluyó con los procesos de migración de ultramar (Dalle, Jorrat \& Rivero, 2018).

En otro texto (Jiménez Zunino, 2017) hemos explorado algunos casos de reproducción malograda en las clases medias cordobesas, cuando los hijos de profesionales incursionan en espacios laborales donde consiguen rápidas carreras en empresas que los tensionan con los proyectos educativos (llegando en algunos casos a abandonarlos). En esos casos que analizamos y que son representativos de una especie de crisis de reproducción de las clases medias, la generación de los padres había sido formada entre las décadas de 1960 y 1990, momento de vigencia de relatos de movilidad social ascendente a través de las inversiones escolares (Kessler, 2003).

Sin embargo, estas fracciones cuentan con diferentes formatos de capital cultural institucionalizado (en el caso de finalizar las carreras) o incorporado (en el caso de tenerlas inconclusas) que canjean en el mercado de trabajo con relativo éxito, a tenor de los salarios percibidos. El perfil de hogares unipersonales es muy llamativo (ver cuadro 1) y encaja con los estilos de vida descritos por Tevik (2006) para las clases medias urbanas con fuerte independencia, capacidad adquisitiva, etc. 
Uno de los casos es Lucía, médica con posgrados. Es la hija menor de un empleado de comercio (que estudió hasta tercer año de medicina) y de una maestra. Ella encarna el mandato familiar de la medicina. La hermana mayor no estudió ninguna carrera, la que sigue estudió medicina (pero sin especialidad, lo que limita su dedicación a guardias y docencia en colegios secundarios); y un hermano fallecido que también quería estudiar medicina. Lucía tiene cargos de responsabilidad en hospitales (jefa de planta y de servicio de ginecología) y combina su inserción en sector público y privado. Actualmente separada, no se plantea tener hijos: "Hoy por hoy, el trabajo es mi vida. De hecho, yo estoy soltera, no tengo novio, no tengo hijos más que la gata y la perra".

En los casos de entrevistados que tienen hijos, la búsqueda de colegio adecuado es una odisea, que cuenta con experiencias de otros padres para orientar, de abuelos que ayudan con el pago de matrículas costosas, de contactos para conseguir entrevistas preferenciales (y eventualmente, plaza en el colegio), etc. Los padres comienzan estas gestiones cuando los niños comienzan la escolarización. Si no encuentran plaza en ese momento, persisten y cambian a los niños de colegio hasta conseguir el lugar deseado ${ }^{16}$.

\section{Clase media alta}

A pesar de las dificultades de medición de este grupo (Benza \& Heredia, 2012), desde el conjunto de variables utilizadas en el análisis, hemos podido identificar como perteneciente a la misma a un $17 \%$ de los hogares; que se asocian a ingresos altos $\left(10^{\circ}\right.$ decil); referente con calificaciones ocupacionales profesionales en puestos directivos, patrones o propietarios. Esta clase está fuertemente masculinizada: las dos fracciones identificadas presentan

\footnotetext{
16 La elección del colegio para los hijos es relatada por los entrevistados de esta clase como una especie de estudio de mercado; ponderan distancia al hogar, valor de la cuota, horario de clases, presencia - y grado- de la religión, público que asiste, contenidos curriculares y vinculares, ideario del centro, etc. Para un desarrollo de este tema, ver el trabajo de Veleda (2003).
} 
una asociación fuerte con jefes de hogar varones. Una de las fracciones (13\% de hogares) cuenta con un elevado capital cultural y ocupaciones asalariadas en categoría profesional en el Estado (enseñanza y cargos directivos); en tanto la otra tiene fuerte relación con propiedad de empresas y sus referentes se ocupan en cargos de dirección en ramas de servicios privados (Gutiérrez y Mansilla, 2015).

En el trabajo cualitativo (8 entrevistas), no obstante, intentamos buscar una representación equilibrada por género y entrevistamos a mujeres también de esta clase social (ver cuadro 2). De los seis entrevistados de la $1^{\circ}$ fracción de la clase media alta, la mitad son mujeres referentes de hogar, ocupadas en altos cargos de la administración estatal (Poder Judicial, instituciones educativas, etc.) y con elevadas credenciales educativas (posgrados). Algunas son referentes de hogar sin cónyuge (separadas o solteras), lo que puede sugerir que sus carreras profesionales han exigido renunciar a algunos roles tradicionales de género ${ }^{17}$. En el caso de Silvana, camarista del Poder Judicial, posiblemente la condición de referente de hogar deviene de la situación de jubilado de su esposo, quien se ha desempeñado como contador de una empresa familiar en la que ahora se desempeña el hijo mediano (licenciado en economía, con maestría en gestión de negocios y estancias formativas en el extranjero).

En la segunda fracción, más rica, relativamente, en capital económico, entrevistamos a dos empresarios importantes de Córdoba que han utilizado también capital cultural para lograr esas posiciones. Ambos se encuentran en su segundo matrimonio actualmente, con cónyuges profesionales (licenciada en relaciones institucionales y odontóloga, respectivamente). No pueden establecerse reglas generales sobre la acumulación de capital cultural, pues la actividad en la que se desempeñan implica sus ló-

\footnotetext{
17 Con un grado de capital relativamente inferior (deducible principalmente por el nivel de ingresos y la jerarquía y categoría ocupacional), en la primera fracción de la clase media también encontramos casos similares.
} 
gicas propias: la empresa de consultoría y marketing de Mariano está vinculada al circuito de producción de conocimiento de las universidades, públicas y privadas, mientras que la empresa de transportes de Antonio requiere, sobre todo, knowhow en logística y contaduría. En ambos casos, las estrategias sucesoras cuentan con hijos de los primeros matrimonios que han sido perfilados para heredar las empresas.

En la reproducción intergeneracional, es patente el patrón de una reconversión de fracción de clase de los hijos de empresarios hacia inversiones en capital cultural institucionalizado (títulos) que es reinvertido luego en el emprendimiento. Uno de los casos es Antonio, quien hereda y amplía una empresa familiar de transportes, por lo que tuvo que abandonar sus estudios superiores (en ciencias económicas). Antonio fue el "elegido" para heredar esta empresa frente a su hermana, quien estudió abogacía. Otra cuestión llamativa es que el cuñado de Antonio (ingeniero agrónomo) se desempeña como gerente de la firma, siguiendo un patrón masculinizado de ocupación en puestos jerárquicos. Los hijos de Antonio están terminando sus carreras universitarias, mientras que también trabajan en la empresa familiar.

En las familias donde la acumulación en capital cultural ha sido más fuerte, encontramos diferencias en las formas de acceso. Hay familias que cuentan con ese capital desde los antecesores. Es el caso de Francisco, director de una escuela prestigiosa, séptimo de una fratría de nueve, en la que solo dos hermanos no terminaron carrera universitaria (padre arquitecto, madre maestra y directora de la misma escuela que Francisco). Su esposa (psicóloga) también cuenta con padres profesionales (contador y nutricionista) y hermanos con títulos universitarios. En este caso, hay un capital cultural fuerte en el origen familiar, ligado a la función pública.

Otro de los casos, en cambio, ha accedido más tarde. Ricardo, mayor de dos hermanos e investigador de un organismo de ciencia y técnica estatal, tuvo que emigrar desde el campo a la ciudad para finalizar sus estudios secundarios mientras trabaja- 
ba en una fábrica tras el fallecimiento del padre. Su madre queda a cargo del hermano menor, mientras se desempeñaba como ama de llaves en una estancia de interior de la provincia. El hermano, como Ricardo, también hizo estudios universitarios y trabaja en la universidad. Sin embargo, parece que el camino recorrido por Ricardo ha sido más dificultoso.

En el análisis cuantitativo, la clase media alta cuenta con una alta proporción de jefatura masculina, pero se observan algunas diferencias en los cónyuges, quienes superan en nivel de estudios a los respectivos referentes de hogar (universitario completo) (Jiménez Zunino \& Giovine, 2017). Esto podría sugerir que los referentes de esta clase no dependen tanto del capital escolar para posicionarse (siendo preponderante el capital económico), en tanto sus cónyuges sí requieren elevada escolaridad, atributo que posiblemente sea eficaz en el mercado matrimonial.

\section{Discusión: Las configuraciones familiares en el estudio de la desigualdad social}

El mayor aporte de este artículo se direcciona en torno a la riqueza analítica que emerge de considerar las configuraciones familiares para el estudio de las dinámicas de desigualdad social. Las clases sociales tienen su soporte empírico en las familias (en tanto que unidades de análisis y de observación), pero esto no significa que sean homogéneas en su interior. Generalmente, el procedimiento utilizado para enclasar familias consiste en tomar la posición del principal sostén de hogar e imputar la clase social de este (que suele ser de género masculino) al resto del grupo familiar. Sin embargo, hemos intentado aquí mostrar el peso de otros factores en la reproducción de las familias: la posición en la fratría, el género, el momento del ciclo de vida familiar y las migraciones internas.

Pensamos que este abordaje, aquí expuesto de modo exploratorio, puede ser fructífero para analizar las aperturas que emergen de una matriz familiar común. A través de la comparación de 
genealogías familiares, se pueden analizar las opciones diferentes para hijos de una misma familia según el género y la posición en la fratría, considerando las siguientes interrogantes: ¿constituyen las familias lugares de reproducción social diferenciado para sus miembros aunque cuenten con los mismos recursos observables (capital económico y cultural)?, ¿cómo se transmiten las disposiciones sobre las estrategias de reproducción social según los repertorios de acción disponibles por los ambientes familiares (saber práctico, aprendizaje corporal, disposiciones semiconscientes de lo valioso y no valioso, etc.)? y ¿de qué modos se distribuyen las energías de soporte, sostenimiento y/o apartamiento de carreras escolares exitosas? Aspectos que, para su adecuada respuesta, precisarían de estudios más focalizados que el que realizamos aquí.

Otra cuestión interesante para reflexionar consiste en el modo en el que los posicionamientos sociales se toman desde un plano sincrónico: no es una sola de las propiedades las que explican el posicionamiento social y la trayectoria. Se percibe eso en las diferencias entre las clases precaria y trabajadora. En algunos casos, quienes están actualmente en la clase trabajadora (con mejores condiciones laborales relativas) tienen menor nivel educativo que quienes están en la clase precaria, debido sobre todo a las condiciones de trabajo (informalidad de los últimos). En ocasiones, los que hoy ocupan posiciones de clase trabajadora, ingresaron a trabajar en fábricas autopartistas, en limpieza o cocina, y luego fueron haciendo carrera interna (mediante cursos y concursos). También interesa resaltar el efecto cohorte (Elder, 1994), que puede explicar algunas propiedades comunes (como el título escolar) en la generación de padres de referentes de diferentes clases sociales. Sin embargo, esto hace pensar también en la gran dispersión de las trayectorias sociales desde orígenes sociales que podrían parecer similares si atendemos solo al capital cultural o al lugar de origen (como puede ser la zona rural).

El periodo de observación que habilita la metodología de trayectorias intergeneracionales es muy amplio e impone el desafío 
de comprender aquello que permanece (en las clases sociales) en los diferentes momentos históricos, sin desconocer también transformaciones importantes a nivel estructural que suponen los diferentes modelos de desarrollo o acumulación. Así, dado este carácter mutante y cambiante de las trayectorias sociales, surge el reto de aprehender el modo en que los agentes de posiciones sociales diferentes reproducen sus vidas y de observar esas transformaciones en la escala micro de las familias. Hemos intentado responder la interrogante sobre aquello que se transmite en las familias cordobesas: ¿es un capital?, ¿un conjunto de ellos?, ¿disposiciones? No solo se trata de pensar en una instancia mecánica de transmisión del mismo capital (que siempre es más visible en el caso del capital económico. Por ejemplo, un negocio), sino de disposiciones a hacer inversiones en una dirección u otra (Rupp, 1995), una condición laboral (ser independiente o autónomo frente a ser asalariado), etc. En el contexto actual, podemos inferir que el modo de reproducción escolar se ha convertido en un modo de generación (Mauger, 2013) que atraviesa e interpela a todas las capas sociales en igual medida, aunque estas pueden adherirse al mismo desde recursos familiares sumamente desiguales y en mercados escolares altamente diferenciados y segmentados. Efectivamente, la interpretación de un modo de reproducción escolar como predominante de una época en las transmisiones intergeneracionales actuales permite dialogar con otros análisis que se realizan actualmente en la región latinoamericana, trabajados en el primer apartado, y que problematizan la expansión de los sistemas educativos con respecto a las posibilidades limitadas de revertirse en mejorar las posiciones sociales (en el mercado de trabajo, en el sistema de estratificación social, etc.). Sin embargo, analizar este modo de reproducción generacional, en el sentido histórico, bajo la lupa de los condicionamientos presentes en las diferentes clases sociales arroja luz sobre la desigualdad en el acceso y permanencia con que cuentan las familias para adquirir los recursos potencial y formalmente disponibles para el conjunto. 
La articulación de metodología cuantitativa y cualitativa constituye otra aportación del artículo. La construcción de un diseño muestral riguroso, apoyado en técnicas estadísticas de análisis factorial y clasificación ha permitido la construcción de perfiles-tipo por clase y fracción de clase, que establece cierta fiabilidad en la selección muestral. Por otra parte, el análisis de los datos en el momento cualitativo, del que aquí solo pudo mostrarse un recorte, supone un desafío de interpretación. No trabajamos con verbatims debido a la limitada extensión de un artículo y a la diversidad de datos. Utilizamos, en cambio, una lectura transversal de los relatos producidos en las entrevistas en profundidad, que permitió captar la interrelación del sistema de prácticas de los agentes, algo que no se encuentra en un fragmento concreto, sino a lo largo del discurso narrado. Esta interpretación transversal, apoyada en la selección muestral, fruto del procesamiento estadístico, se conecta también con la dimensión histórica de las prácticas relatadas. La virtualidad analítica que ha supuesto esta técnica de análisis nos lleva a alertar sobre el uso de programas informáticos que parcelan en bloques los discursos, aislándolos de la totalidad de significados producidos en la entrevista.

Por último, las páginas precedentes también constituyen un modesto aporte a la reflexividad metodológica que pueden contribuir los enfoques cualitativos combinados con técnicas cuantitativas. Hemos intentado ilustrar, a propósito del análisis diferentes premisas metodológicas: a) la información provista por un informante sobre el grupo familiar que posibilita ganar en productividad de datos (Bertaux, 1995); b) la validez hermenéutica de los datos de los entrevistados, porque son fuente tanto de información como de significados (Bertaux, 2005); y c) arriesgar la interpretación (Lahire, 2006) dentro de un marco analítico que permita conectar los datos vertidos en un relato biográfico con los datos de carácter estructural —obtenidos por procedimientos estadísticos y por estudios históricos y sociológicos que enmarcan la interpretación. En suma, se trata de construir herramientas de análisis que reintroduzcan la experiencia de los agentes para identificar el 
modo en que los procesos estructurales inciden dialécticamente en las vidas de los sujetos a la vez que configuran esas estructuras.

\section{Referencias}

Álvarez, M. F. (2013). Educación en cifras. Nivel inicial y primario en Córdoba. 2002-2010. Córdoba: Centro de Estudios de Población y Desarrollo. Disponible en: http://www.nuestracordoba. org.ar/sites/default/files/informe-educacion-Cepyd.pdf

Beaud, S. \& Pialoux, M. (2014). Una nueva mirada sobre la condición obrera. Revista de Trabajo, (12), 135-158. Disponible en: http:// www.trabajo.gov.ar/downloads/estadisticas/2014n12_revistaDeTrabajo.pdf

Benza, G. \& Heredia, M. (2012). La desigualdad desde arriba: Ejercicio de reconstrucción de las posiciones sociales más altas en Buenos Aires. Ponencia presentada en las VII Jornadas de Sociología de la Universidad Nacional de La Plata, La Plata, Argentina. Disponible en: http://www.memoria.fahce.unlp.edu.ar/ trab_eventos/ev.1719/ev.1719.pdf

Bertaux, D. (1995). Social genealogies commented on and compared: An instrument for observing social mobility processes in the "longue durée". Current Sociology, 43(2), 69-88. Disponible en: https:/ / doi.org/10.1177/001139295043002009

Bertaux, D. (2005). Los relatos de vida. Perspectiva etnosociológica. Barcelona: Bellaterra.

Bertaux, D. \& Bertaux-Wiame, I. (2009). Heritage and its lineage: A case history of transmission and social mobility over five generations. En D. Bertaux \& P. Thompson (Eds.), Pathways to social class: a qualitative approach to social mobility (pp. 62-97). New Brunswick: Transaction Publishers.

Bertaux, D. \& Thompson, P. (2009). Introduction. En D. Bertaux \& P. Thompson (Eds.), Pathways to social class: a qualitative approach to social mobility (pp. 1-31). New Brunswick: Transaction Publishers.

Bourdieu, P. (1997). Razones prácticas. Barcelona: Anagrama.

Bourdieu, P. (1998). La distinción: Criterios y bases sociales del gusto. Madrid: Taurus.

Bourdieu, P. (2011). Las estrategias de reproducción social. Buenos Aires: Siglo XXI. 
Brunner, J. (Ed.) (2011). Educación superior en Iberoamérica. Informe 2011. Santiago de Chile: Centro Interuniversitario de Desarrollo.

Carabaña, J. (1999). Dos estudios sobre movilidad intergeneracional. Madrid: Fundación Argentaria-Visor.

Chauvel, L. (2006). Les classes moyennes à la dérive. París: Du Seuil et Le République des Idées.

Chauvel, L. (2016). La spirale du déclassement. Essai sur la societé des illusions. París: Du Seuil.

Collin, F. (2003). Les trans parents. EMPAN, 50(2), 14-23. Disponible en: https://doi.org/10.3917/empa.050.0014

Courgeau, D. (1998). New methodological approaches in the social sciences. An overview. Population. An English Selection, 10 (1), 1-9. Disponible en: www.persee.fr/doc/pop_00324663_1998_hos_10_1_6820

Crompton, R. (1997). Clase y estratificación. Una introducción a los debates actuales. Madrid: Tecnos.

Dalle, P., Jorrat, J. \& Rivero, M. (2018). Movilidad social intergeneracional. En J. I. Piovani \& A. Salvia (Eds.), La Argentina en el siglo XXI (pp. 147-180). Buenos Aires: Siglo XXI.

Decreto 1602/2009 (2009). Asignaciones familiares. Régimen general y disposiciones especiales. Boletín Oficial de la República Argentina, Buenos Aires, 30 de octubre de 2009.

Elder, G. H. (1994). Time, human agency, and social change: Perspectives on the life course. Social Psychology Quarterly, 57(1), 4-15. Disponible en: doi: $10.2307 / 2786971$

Fine, A. (2006). Les fratries en Europe. Apercu sur quelques orientations de recherches en antropologie. En M. Oris, Brunet, G., Widmer, E. \& Bideau, A. (Eds.), Les fratries. Une démographie sociale de la germanité (pp. 1-27). Berna: Peter Lang.

Franco, R. \& Hopenhayn, M. (2010). Las clases medias en América Latina: Historias cruzadas y miradas diversas. En R. Franco, M. Hopenhayn \& A. León (Eds.), Las clases medias en América Latina. Retrospectiva y nuevas tendencias (pp. 7-41). Buenos Aires: CEPAL- Siglo XXI.

Gaulejac De, V. (2003). Malaise dans la transmisión. EMPAN, 50(2), 3237. Disponible en: https:/ / doi.org/10.3917/empa.050.0032

Gómez-Rojas, G. \& Riveiro, M. (2014). Hacia una mirada de género en los estudios de movilidad social: Interrogantes teórico-me- 
todológicos. Boletín Científico Sapiens Research, 4(1), 26-31. Disponible en: http://hdl.handle.net/11336/34338

Gutiérrez, A. (2005). Pobre como siempre. Estrategias de reproducción social en la pobreza. Córdoba: Ferreyra.

Gutiérrez, A. \& Mansilla, H. (2015). Clases y reproducción social: el espacio social cordobés en la primera década del siglo XXI. Política y Sociedad, 52(2), 409-442. Disponible en: https:// doi.org/10.5209/rev_POSO.2015.v52.n2.44467

Jedlicki, F. (febrero, 2018). La mobilité sociale à l'épreuve des économies affectives. Trajectoires scolaires et résidentielles de fratries petites-moyennes rurales. Ponencia presentada en Seminario Interno de l'Unité de Recherche 6 (Ined).

Jiménez Zunino, C. (2011). Desclasamiento y reconversiones en las trayectorias de los migrantes argentinos de clases medias (Tesis doctoral). Universidad Complutense de Madrid, Madrid. Disponible en: http:/ / eprints.ucm.es/17260/1/T33354.pdf

Jiménez Zunino, C. (2015). Trayectorias sociales de los migrantes de clases medias argentinas: Reproducción, reconversión y desclasamiento. Sociología Histórica, (5), 389-427. Disponible en: http://revistas.um.es/sh/issue/view/13861/showToc

Jiménez Zunino, C. (2017). ¿Estudiar o trabajar? Dilemas en la formación de profesionales de clase media en Córdoba (Argentina). Revista Propuesta Educativa, 2(48), 34-44. Disponible en: http://www.propuestaeducativa.flacso.org.ar/articulo. php? num $=48 \&$ id $=64$

Jiménez Zunino, C. \& Assusa, G. (2017). ¿Desigualdades de corta distancia? Trayectorias y clases sociales en Córdoba. Revista Mexicana de Sociología, 79(4), 837-874. Disponible en: http:/ / revistamexicanadesociologia.unam.mx/index.php/rms/ article/view /57692/51156

Jiménez Zunino, C. \& Giovine, M. (2017). Terminar el secundario en Córdoba: Desigualdad educativa y nivel medio en la última década. Revista Páginas de Educación, 10(2), 21-43. Disponible en: http://revistas.ucu.edu.uy/index.php/paginasdeeducacion/article/view/1419/1418

Jorrat, J. (2008). Exploraciones sobre movilidad de clases en Argentina: 20032004. (Documento de Trabajo No 52), Buenos Aires: Instituto de Investigación Gino Germani, Facultad de Ciencias 
Sociales, UBA. Disponible en: http:/ / biblioteca.clacso.edu. ar/Argentina/iigg-uba/20100720111800/dt52.pdf

Kaplan, C. \& Piovani, J. I. (2018). Trayectorias y capitales socioeducativos. En J. I. Piovani \& A. Salvia (Ed.), La Argentina en el siglo XXI (pp. 221-269). Buenos Aires: Siglo XXI.

Kessler, G. (2003). Empobrecimiento y fragmentación de la clase media argentina. Proposiciones, 34, 1-11. Disponible en: https:// docplayer.es /7230784-Empobrecimiento-y-fragmentacionde-la-clase-media-argentina.html

Kessler, G. \& Espinosa, V. (2003). Movilidad social y trayectorias en Buenos Aires. Rupturas y algunas paradojas. Santiago de Chile: CEPAL.

Lahire, B. (1995). Tableaux de famille. Heurs et malheurs scolaires en milieux populares. París: Gallimard-Le Seuil.

Lahire, B. (2006). El espíritu sociológico. Buenos Aires: Manantial.

Ley de Educación Nacional. (2006). Ley 26.206. Buenos Aires: Senado y Cámara de Diputados de la Nación de Argentina.

Martín Criado, E. (1998). Producir la juventud. Madrid: Istmo.

Luci, F. \& Gessaghi, V. (2015). Familias tradicionales y élites empresarias en Argentina: individuación y solidaridad en la construcción y sostén de las posiciones de privilegio. Politica. Revista de Ciencia Política, 54(1), 53-84. Disponible en: https:/ / doi:10.5354/0716-1077.2016.42699

Mauger, G. (2013). Modos de generación de las generaciones sociales. Sociología Histórica , 2, 131-151. Disponible en: https: / / revistas.um.es/sh/article/view/188951/155591

Mediavilla, M. \& Calero, J. (2010). Movilidad educativa en Latinoamérica. Un estudio para seis países. Revista Española de Educación Comparada, 16, 287-303.

Mora Salas, M. (2008). En el borde: riesgo de empobrecimiento de los sectores medios en tiempos de ajuste y globalización. Buenos Aires: CLACSO - CROP.

Perona, N. \& Schiavoni, L. (2018). Estrategias familiares de reproducción social En J. I. Piovani \& A. Salvia (Ed.), La Argentina en el siglo XXI (pp. 467-496). Buenos Aires: Siglo XXI.

Peugny, C. (2012). L’ expériencie vécu de la mobilité social: les poids de la fratrie. Informations sociales 5 (173), 94-101. Disponible 
en: https://www.cairn.info/revue-informations-sociales2012-5-page-94.htm

Rupp, J. (1995). Les classes populares dans un espace social à deux dimensions. Actes de la Recherche en Sciences Sociales, 109, 9398. Disponible en: https://www.persee.fr/doc/arss_03355322_1995_num_109_1_3156

Ruta, C. (2015). El futuro de la universidad argentina. EnJ. C. Tedesco (Ed.), La educación argentina hoy: la urgencia del largo plazo (pp. 319-350). Buenos Aires: Siglo XXI.

Solís, P. (2018). Barreras estructurales a la movilidad social intergeneracional en México. Un enfoque multidimensional. México D.F.: CEPAL - Naciones Unidas, México.

Terrail, J. P. (1984). Familles ouvrières, école, destin social (1880-1980). Revue Française de Sociologie, XXV, 421-436.

Tevik, J. (2006). Porteñologics. El significado del gusto y la moralidad en la clase media profesional porteña. Buenos Aires: Antropofagia.

Torrado, S. (2003). Historia de la familia en la Argentina moderna (18702000). Buenos Aires: Ediciones de la Flor.

Veleda, C. (2003). Mercados educativos y segregación social. Las clases medias y elección de la escuela en el Conurbano Bonaerense. Documento de Trabajo $\mathrm{N}^{\circ} 12$, CIPPEC.

\section{Fuentes:}

INDEC, Base usuario ampliada de la Encuesta Permanente de Hogares, Tercer trimestre 2011, Región Gran Córdoba. Disponible en: www.indec.mecon.gov.ar 


\section{Anexo}

Cuadro 3

Muestreo representativo según fracciones y clases

\begin{tabular}{|l|l|}
\hline Clase & Fracciones \\
\hline \multirow{2}{*}{$\begin{array}{l}\text { Precariado } 20 \%: \\
9 \text { entrevistas }\end{array}$} & $1^{\circ}$ Fracción: 3 entrevistados \\
\cline { 2 - 2 } $\begin{array}{l}\text { Trabajadora 35\%: } \\
13 \text { entrevistas }\end{array}$ & $2^{\circ}$ Fracción: 6 entrevistados \\
\hline \multirow{2}{*}{$\begin{array}{l}\text { Media } 29 \%: \\
13 \text { entrevistas }\end{array}$} & $1^{\circ}$ Fracción: 7 entrevistados \\
\hline \multirow{2}{*}{$\begin{array}{l}\text { Media alta } 17 \%: \\
8 \text { entrevistas }\end{array}$} & $1^{\circ}$ Fracción: 6 entrevistados 5 entrevistados \\
\cline { 2 - 2 } & $2^{\circ}$ Fracción: 8 entrevistados \\
\hline
\end{tabular}

Nota: Elaboración colectiva de equipo durante fase de selección de entrevistas 